\title{
Coexistent gastric MALT lymphoma and Kaposi sarcoma in an HIV positive patient
}

\author{
Runjan Chetty, Shunmugan V Pillay
}

\begin{abstract}
A 47 year old HIV positive male presented with haematemesis and epigastric pain. A gastrectomy was performed for intractable bleeding. The cause of the haematemesis proved to be a Kaposi sarcoma of the stomach which had resulted in mucosal ulceration. Several other smaller foci of Kaposi sarcoma were also present. Coexistent with the Kaposi sarcoma was a dense lymphoid infiltrate with lymphoid follicles and reactive germinal centres. Centrocyte-like cells caused marked effacement and destruction of gastric glands with the formation of lymphoepithelial lesions, typical of a MALT lymphoma. These cells were of $B$ cell lineage and some expressed the HIV antigen, p24. Follicular dendritic cells and macrophages within germinal centres were also p24 positive. Immunohistochemistry and in situ hybridisation did not detect Epstein-Barr virus. Although Helicobacter pylori was not identified by light microscopy in the sections sampled, this does not preclude its possible role, with other cofactors such as HIV, in the causation of the MALT lymphoma.

(F Clin Pathol 1999;52:313-316)
\end{abstract}

Keywords: HIV; malt lymphoma; Kaposi sarcoma; stomach

The immunocompromised state, which can result from a variety of causes, can lead to an increased incidence of non-Hodgkin lymphomas. In patients with congenital immunodeficiencies, at least $4 \%$ will develop some form of malignancy, with leukaemia/lymphoma accounting for $60 \%$ of these. ${ }^{1}$ Similarly, patients with iatrogenic immunosuppression, autoimmune diseases, and AIDS also have a propensity for developing malignancies. In the case of HIV/AIDS, high grade B cell non-Hodgkin lymphomas and Kaposi sarcoma collectively account for $95 \%$ of the malignancies in this group of patients. ${ }^{23}$ Low grade lymphomas in the HIV/AIDS setting are rare, and only a few cases have been documented. ${ }^{4-9}$ Among these low grade lymphomas, gastric mucosa associated lymphoid tissue (MALT) lymphomas (marginal zone lymphoma of MALT) are even rarer, with only four cases reported in this particular setting. ${ }^{4} 679$

Kaposi sarcoma in any of its epidemiological forms may have visceral involvement, but this most often occurs in the HIV, epidemic type. Kaposi sarcoma of the gastrointestinal tract, especially the proximal parts, in AIDS and HIV positive patients is a frequent occurrence, and necropsy studies have shown gastrointestinal tract involvement in $77-100 \%$ of cases. ${ }^{10}{ }^{11}$

The combination of a low grade MALT lymphoma and Kaposi sarcoma occurring simultaneously in the stomach of an HIV positive patient has not, to the best of our knowledge, been described before.

\section{Case report}

A 47 year old black male presented with haematemesis and epigastric pain of unknown duration. He did not have any significant past history, and on examination appeared pale. No other positive physical signs were noted. Serological examination showed him to be HIV positive. An endoscopy was performed and this revealed a large ulcer in the body of the stomach. Several biopsies were taken. The patient continued to have bouts of haematemesis and a partial gastrectomy was performed.

EXAMINATION OF THE TISSUE

All tissue examined was formalin fixed, routinely processed, and paraffin embedded. In addition to routine haematoxylin and eosin stains, the specimen was subjected to a panel of immunohistochemical markers (outlined in table 1), and in situ hybridisation for EpsteinBarr virus using EBERs 1 and 2.

\section{Results}

GROSS EXAMINATION

The gastrectomy specimen measured $12 \times 9$ $\mathrm{cm}$ and contained a $3 \mathrm{~cm}$ ulcer in the body of the stomach along the lesser curve. The ulcer crater appeared haemorrhagic, but discrete tumour nodules were not seen. The edges of the ulcer were sharply punched out. The remainder of the mucosa appeared normal to the naked eye. Occasional lymph nodes were present within the omentum, the largest measuring $1 \mathrm{~cm}$ in maximum diameter.

\section{LIGHT MICROSCOPY}

The features of the initial gastric biopsies were of chronic active gastritis with areas suggestive of MALT lymphoma. Helicobacter pylori ( $H$ py-

Table 1 Immunohistochemical antibodies

\begin{tabular}{lll}
\hline Antibody & Dilution & Source \\
\hline CD20 & $1 / 100$ & Dakopatts, Copenhagen \\
CD79a & $1 / 100$ & Dakopatts, Copenhagen \\
CD3 & $1 / 75$ & Dakopatts, Copenhagen \\
CAM 5.2 & Prediluted & Becton Dickinson, USA \\
AE1/3 & $1 / 1600$ & Signet Labs, USA \\
p24 & $1 / 20$ & Dakopatts, Copenhagen \\
EBV-LMP-1 & $1 / 65$ & Dakopatts, Copenhagen \\
$\kappa / \lambda$ & Prediluted & Dakopatts, Copenhagen \\
CD 31 & $1 / 30$ & Dakopatts, Copenhagen \\
CD 34 & Prediluted & Dakopatts, Copenhagen \\
\hline
\end{tabular}

Accepted for publication 10 November 1998
Department of of Natal School of 7, Congella 4013 Durban, South Africa S V Pillay

Correspondence to: Professor Chetty. 


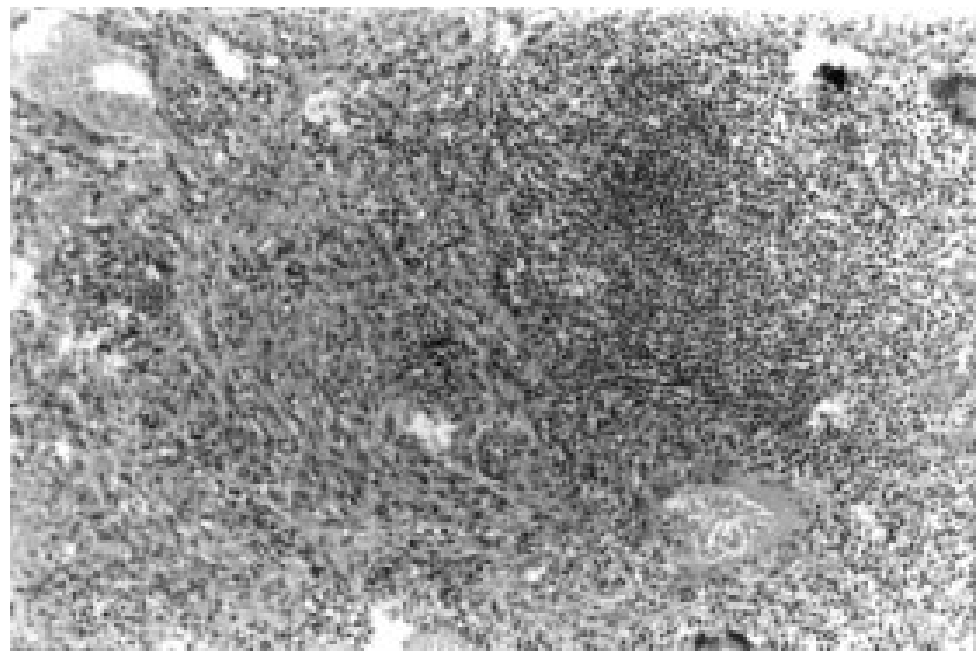

Figure 1 Nodular spindle cell proliferation of Kaposi sarcoma (left) with the centrocyte-like cells of the MALT lymphoma (right). The Kaposi sarcoma appeared as discrete nodules within the lymphoid infiltrate. (Haematoxylin and eosin stain.)

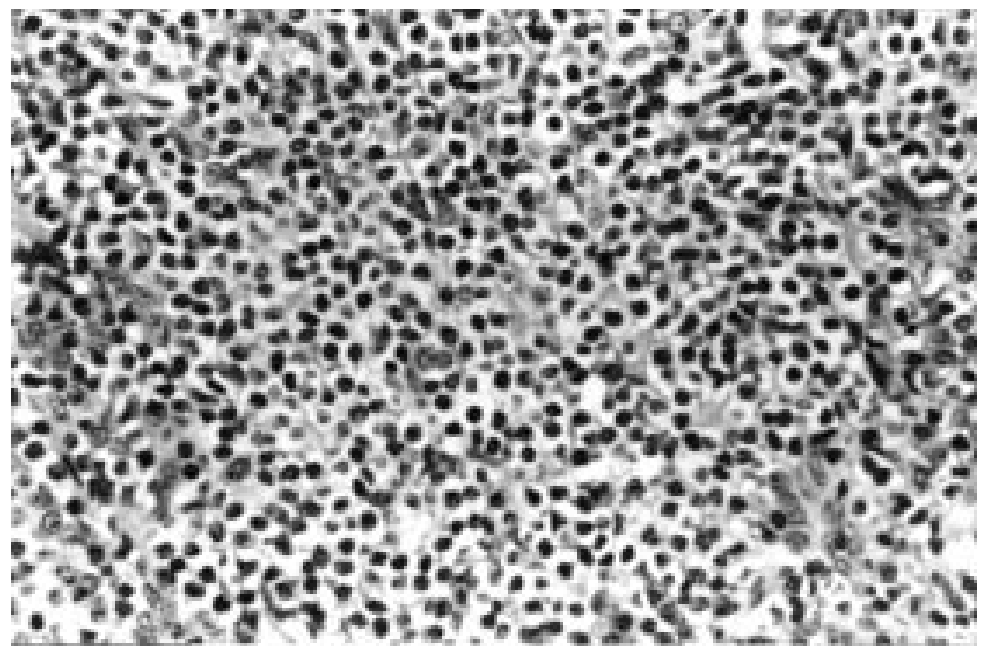

Figure 2 A confluent sheet of centrocyte-like cells which show characteristic clear cytoplasm imparting a "halo" appearance. (Haematoxylin and eosin stain.)

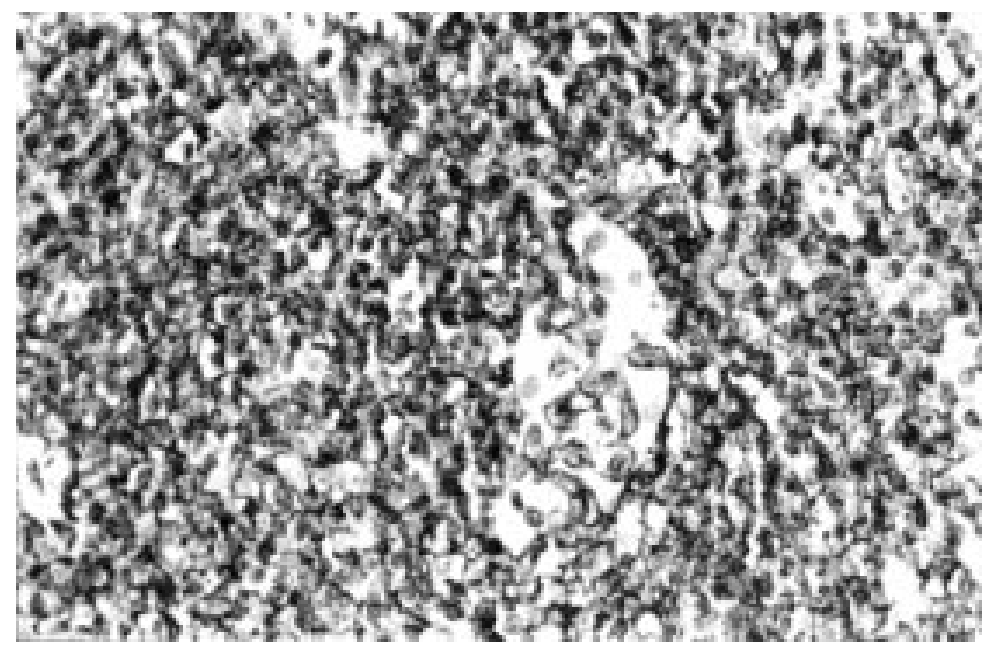

Figure 3 The centrocyte-like cells expressed CD20 antigen strongly. Here the neoplastic B cells can be seen destroying a gastric gland with formation a lymphoepithelial lesion. (Anti-CD20, ×347.) lori) organisms were not identified. As these were superficial biopsies further comment could not be made.

The gastrectomy specimen showed typical features of a low grade MALT lymphoma and Kaposi sarcoma (fig 1). A dense lymphoid infiltrate with prominent lymphoid follicles containing reactive germinal centres occupied the entire mucosa. Occasional lymphoid follicles displayed "follicular colonisation," where the centrocyte-like cells were present within the germinal centres. In addition, the diagnostic centrocyte-like cells occupied the entire lamina propria and were located between the lymphoid follicles (fig 2). The centrocyte-like cells were slightly larger than centrocytes; several had a clear cytoplasm and were aggregated focally in sheets (fig 2). These cells replaced gastric glands and formed characteristic lymphoepithelial lesions. Admixed with the centrocyte-like cells were plasma cells, which were found predominantly around the lymphoid follicles and in the interfollicular areas. Organisms of $H$ pylori were not detected, nor were other organisms seen. The omental lymph nodes showed follicular hyperplasia and no obvious involvement by either MALT lymphoma or Kaposi sarcoma was noted.

Within the mucosa and submucosa, several discrete foci of Kaposi sarcoma were noted. The interface between the MALT lymphoma and Kaposi sarcoma was sharp and no merging between the lesions was apparent. These comprised spindle shaped cells forming slit-like vascular spaces with extravasated erythrocytes. Occasional cytoplasmic hyaline globules and mitoses were present within the spindle cell proliferation. Associated deposits of haemosiderin were also present, and perilesional plasma cells were obvious. Focally, the smaller foci of Kaposi sarcoma had ulcerated the surface lining mucosa, and the large ulcer noted macroscopically was caused by an ulcerated nodule of Kaposi sarcoma.

IMMUNOHISTOCHEMISTRY

The centrocyte-like cells were of B cell lineage and marked strongly for both CD20 (fig 3) and CD79a. Several CD3 positive T cells were present within the germinal centres of the lymphoid aggregates, as well as admixed with the neoplastic centrocyte-like cells within the lamina propria. The $\mathrm{T}$ cells did not participate in lymphoepithelial lesions. The epithelial markers CAM 5.2 and AE1/3 both highlighted the extensive destruction of the gastric glands (fig 4). Several of the follicular dendritic cells in the reactive germinal centres were strongly immunolabelled with p24 (fig 5). In "colonised" follicles, p24 positive follicular dendritic cells were also noted. Many (approximately $30-40 \%$ ) of the centrocyte-like cells were also p24 positive. Plasma cells associated with the MALT lymphoma and those around the Kaposi sarcoma nodules were polyclonal for $\kappa$ and $\lambda$ light chains. The centrocyte-like cells did not show unequivocal light chain restriction.

The Kaposi sarcoma cells were strongly positive for both CD 31 and CD 34. These cells were immunonegative for $\mathrm{p} 24$. Both the 


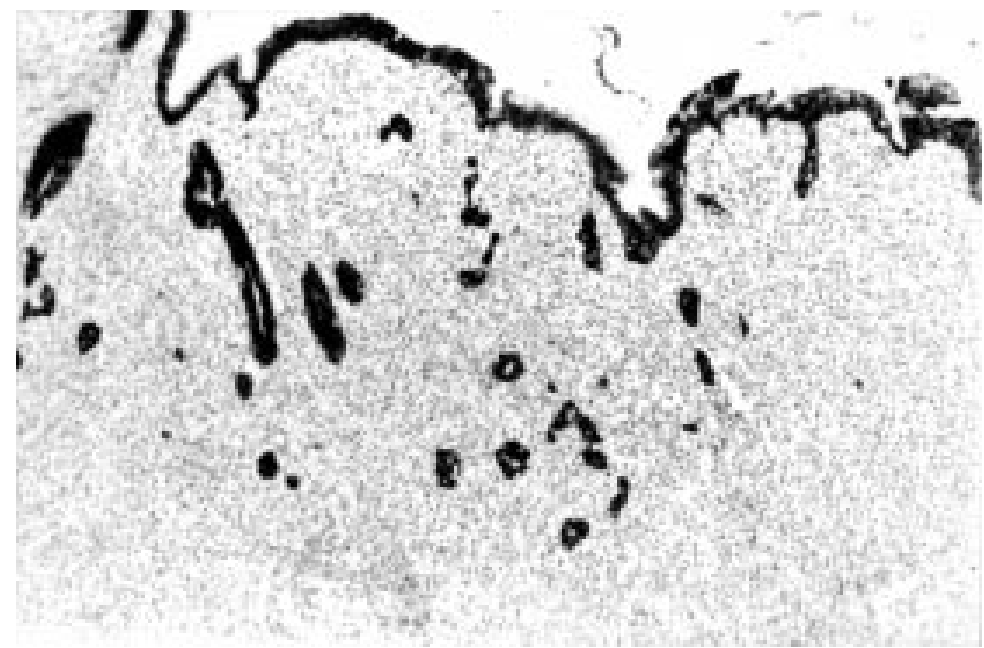

Figure 4 Epithelial marker (CAM 5.2) revealing the extensive replacement of gastric glands by lymphoid cells within the lamina propria. Some glands show partial effacement by the centrocyte-like cells with the formation of lymphoepithelial lesions. (Anti-CAM 5.2, $\times 35$ )

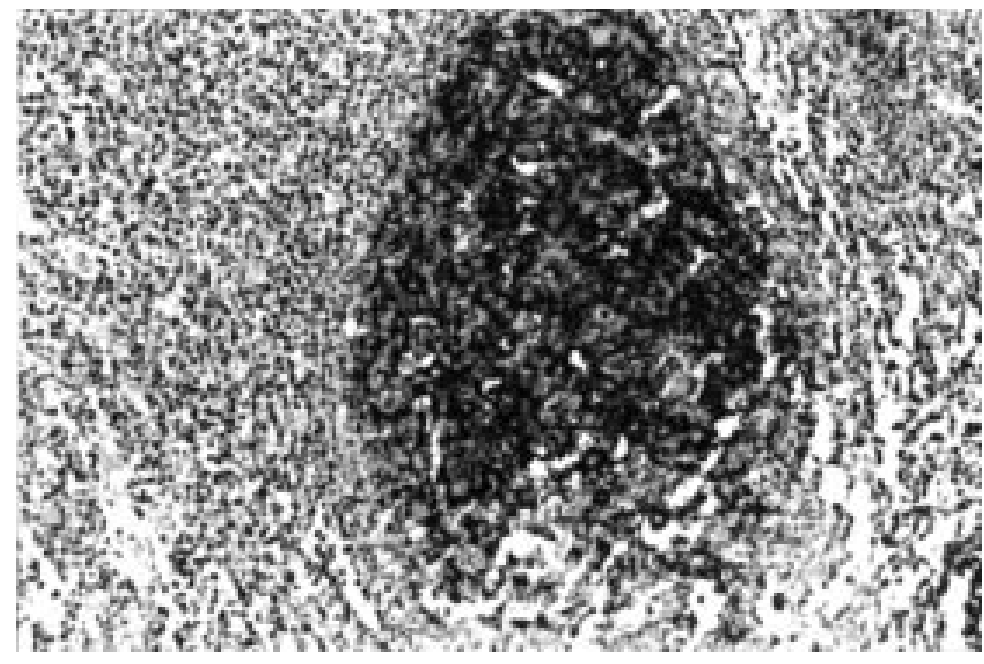

Figure 5 p24 immunostaining of a reactive lymphoid follicle with the follicular dendritic cells and macrophages showing intense immunolabelling. Some of the lymphoid cells outside the mantle zone are also positive. (Anti-p24, ×347).

MALT lymphoma and the Kaposi sarcoma were negative for EBV-LMP-1.

IN SITU HYBRIDIZATION

Both lesions were negative for EBERs 1 and 2.

\section{Discussion}

The coexistence of low grade MALT lymphoma and Kaposi sarcoma in an HIV positive patient reflects the occurrence of two malignancies that are pathogenically related to $H$ pylori and Kaposi sarcoma associated herpes virus (KSHV) respectively. ${ }^{12}{ }^{13}$ The causal relation between $H$ pylori and gastric MALT lymphoma is now a well accepted fact and it is identified in more than $90 \%$ of cases of gastric MALT lymphoma. ${ }^{13-15}$ There is considerable epidemiological and experimental evidence leading to a proposed pathogenic model for gastric MALT lymphoma ${ }^{13}$ : as a result of $H p y-$ lori infection, both $\mathrm{T}$ and $\mathrm{B}$ cells are recruited to the gastric mucosa; some of the $\mathrm{B}$ cells acquire a genetic abnormality and this results in a monoclonal proliferation; with $\mathrm{T}$ cell assistance and further genetic aberrations, low grade MALT lymphoma results.

A causal relation between KSHV and Kaposi sarcoma has been established. ${ }^{12}$ KSHV or human herpes virus- 8 shows sequence homology to Epstein-Barr virus (EBV). EBV itself has been implicated in the pathogenesis of lymphoproliferative disorders, especially in the posttransplant immunosuppression setting. However, Ott and colleagues have found that EBV does not play a role in the pathogenesis of low grade MALT lymphomas. ${ }^{16}$ In the case presented here, both immunohistochemistry and in situ hybridisation for EBV were negative, supporting this notion. The absence of demonstrable light chain restriction in the centrocytelike cells by immunohistochemistry does not exclude the possibility that the lesion may indeed be monoclonal. The extent and the morphology of the lymphoid infiltrate in the stomach was characteristic of a MALT lymphoma, thus obviating the need to demonstrate monoclonality, which in itself is not a prerequisite for the diagnosis of these lesions. There is debate over the incidence of $H$ pylori in HIV patients. It has been stated that the incidence of $H$ pylori infection in HIV/AIDS patients ranges from $3 \%$ to $40 \%{ }^{17-20}$ The consensus of opinion from published reports is that the incidence of $H$ pylori in these patients is less than in HIV negative control populations. ${ }^{19}$ In this case only light microscopy was performed to identify $H$ pylori; thus its existence cannot be excluded categorically. It still may be implicated in the pathogenesis of the MALT lymphoma.

The strong immunopositivity for p 24 in both follicular dendritic cells and tumour lymphocytes indicates a strong HIV presence. It has been shown that $T$ cells are essential for the proliferation of the tumour B cells in low grade MALT lymphoma. ${ }^{21}{ }^{22}$ In the case under discussion, several $\mathrm{T}$ cells were present (as seen immunohistochemically) and conceivably these cells provided sufficient assistance for B cell proliferation and hence the development of the low grade MALT lymphoma. It is well known that HIV is harboured in follicular dendritic cells and eventually leads to the destruction of these cells. The p24 immunostaining in this case showed an intact follicular dendritic pattern, with HIV entrapped extracellularly between the interdigitating cell processes of the dendritic cells. It is then possible to speculate that there is a high concentration of HIV attached to the follicular dendritic cells within the germinal centres, and this acts as the source of immunosuppression.

A process of "sequential neoplasia" has been suggested, wherein HIV expressing macrophages become clonal and provide a milieu conducive for the development of Kaposi sarcoma. ${ }^{23}$ Immunosuppression and the role of KSHV are the major pathogenic mechanisms that have been advanced for the development of Kaposi sarcoma. It is possible that HIV infection induced the development of Kaposi sarcoma because of immune deficiency. Kaposi sarcoma, in turn, may have led to a local immune response or lymphoproliferation in the 
form of a MALT lymphoma. Although no obvious direct aetiological link between the two lesions is apparent, immunodeficiency or immune dysregulation would appear to be important.

In conclusion, this case shows the concurrence of two HIV associated conditions: an uncommon, low grade gastric MALT lymphoma and the commoner lesion, Kaposi sarcoma. While the coexistence of these two lesions may be purely coincidental, it is possible that they are manifestations of HIV induced immune dysfunction.

1 Gaffey MJ, Weiss LM. Association of Epstein-Barr virus with human neoplasia. Pathol Annu 1991;2:55-74.

2 Danzig JB, Brandt LJ, Reinus JF, et al. Gastrointestina malignancy in patients with AIDS. Am f Gastroentero 1991;86:715-18.

3 Friedman SL, Wright TL, Altman DF. Gastrointestinal Kaposi's sarcoma in patients with AIDS. Endoscopic and autopsy findings. Gastroenterology 1985;89:102-8.

4 Coker RJ, Lau R, Isaacson PG, et al. Mucosa-associated gastric lymphoma occurring in an HIV-antibody-positive patient. AIDS 1992;6:336-7.

5 Joshi VV, Gagnon GA, Chadwick EG, et al. The spectrum of mucosa-associated lymphoid tissue lesions in pediatric patients infected with HIV. A clinicopathologic study of six cases. Am f Clin Pathol 1997;107:592-600.

6 Rivas C, Prieto E, Sanchez-Fayos P, et al. Linfomas gastrointestinales tipo MALT en pacientes con infeccion

7 Rodriguez-Sanjuan JC, Naranjo A, Echevarria S, et al. Primary gastric lymphoma in an HIV-infected patient. $f$ Acquir Immune Defic Syndr Hum Retrovirol 1996;13:467-8.

8 Teruya-Feldstein J, Temeck BK, Sloas MM, et al. Pulmonary malignant lymphoma of mucosa-associated lymphoid tissue (MALT) arising in a pediatric HIV-positive patient. Am F Surg Pathol 1995; 19:357-63.

9 Wotherspoon AC, Diss TC, Pan L, et al. Low grade gastric B-cell lymphoma of mucosa associated lymphoid tissue in immunocompromised patients. Histopathology 1996;28: 129-34.
10 Longo DL, Steis RG, Lane HC, et al. Malignancies in the AIDS patient: natural history, treatment strategies and preliminary results. Ann NY Acad Sci 1984;437:421-30.

11 Rotterdam H, Tsang P. Gastrointestinal disease in the mmunocompromised patient. Hum Pathol 1994;25:112340.

12 Dictor M, Rambech E, Way D, et al. Human herpesvirus 8 (Kaposi's sarcoma-associated herpesvirus) DNA in Kaposi's sarcoma cell lines, endothelial Kaposi's sarcoma simulators, and the skin of immunosuppressed patients. $A m \mathcal{F}$ Pathol 1996;148:2009-16.

13 Isaacson PG. Gastrointestinal lymphoma. Hum Pathol 1994;25:1020-9. 1991;86:715-18.

14 Isaacson PG. Recent developments in our understanding of gastric lymphomas. Am F Surg Pathol 1996:20:S1-7.

15 Wotherspoon AC, Ortiz-Hidalgo C, Falzon MR, Isaacson PG. Helicobacter pylori-associated gastritis and primary B-cell gastric lymphoma. Lancet 1991;338:1175-6.

16 Ott G, Kirchner T, Muller-Hermelink HK. Primary gastric lymphoma is rarely associated with Epstein-Barr virus. Virchows Arch B Cell Pathol 1993;64:287-91.

17 Battan R, Raviglione MC, Palagiano A, et al. Helicobacter pylori infection in patients with acquired immune deficiency syndrome. Am f Gastroenterol 1990;85:1576-9.

18 Edwards PD, Carrick J, Turner J, et al. Helicobacter pyloriassociated gastritis is rare in AIDS: antibiotic effect or a consequence of immunodeficiency. Am 7 Gastroenterol 1991;86:1761-4.

19 Eidt S, Schrappe M, Fischer R. Analysis of antral biopsy specimens for evidence of acquired mucosa-associated lymphoid tissue in HIV1-seropositive and HIV1-negative patients. Scand F Gastroenterol 1995;30:635-9.

20 Marano BJ, Smith F, Bonanno CA. Helicobacter pylori prevalence in acquired immunodeficiency syndrome. $A m \mathcal{F}$ Gastroenterol 1993;88:689-90.

21 Hussell T, Isaacson PG, Crabtree JE, et al. Helicobacter pylori-specific tumour-infiltrating $\mathrm{T}$ cells provide contact dependent help for the growth of malignant B cells in lowgrade gastric lymphoma of mucosa-associated lymphoid tissue. F Pathol 1996;178:122-7.

22 Wright DH. Lymphomas of mucosa-associated lymphoid tissue and antigen drive. $\mathcal{F}$ Pathol 1996;178:111-12.

23 McGrath MS, Shiramizu BT, Herndier BG. Identification of a clonal form of HIV in early Kaposi's sarcoma: evidence for a novel model of oncogenesis, "sequential neoplasia". 7 Acquir Immune Defic Syndr Hum Retrovirol 1995;8:379-85. 